This item was submitted to Loughborough's Research Repository by the author.

Items in Figshare are protected by copyright, with all rights reserved, unless otherwise indicated.

\title{
Insulated skin temperature as a measure of core body temperature for individuals wearing CBRN protective clothing
}

PLEASE CITE THE PUBLISHED VERSION

http://dx.doi.org/10.1088/0967-3334/34/11/1531

PUBLISHER

(C) Institute of Physics and Engineering in Medicine

VERSION

AM (Accepted Manuscript)

LICENCE

CC BY-NC-ND 4.0

\section{REPOSITORY RECORD}

Richmond, Victoria, D.M. Wilkinson, S.D. Blacker, F.E. Horner, J. Carter, George Havenith, and M.P. Rayson. 2019. "Insulated Skin Temperature as a Measure of Core Body Temperature for Individuals Wearing CBRN Protective Clothing". figshare. https://hdl.handle.net/2134/13456. 
This item was submitted to Loughborough's Institutional Repository (https://dspace.lboro.ac.uk/) by the author and is made available under the following Creative Commons Licence conditions.

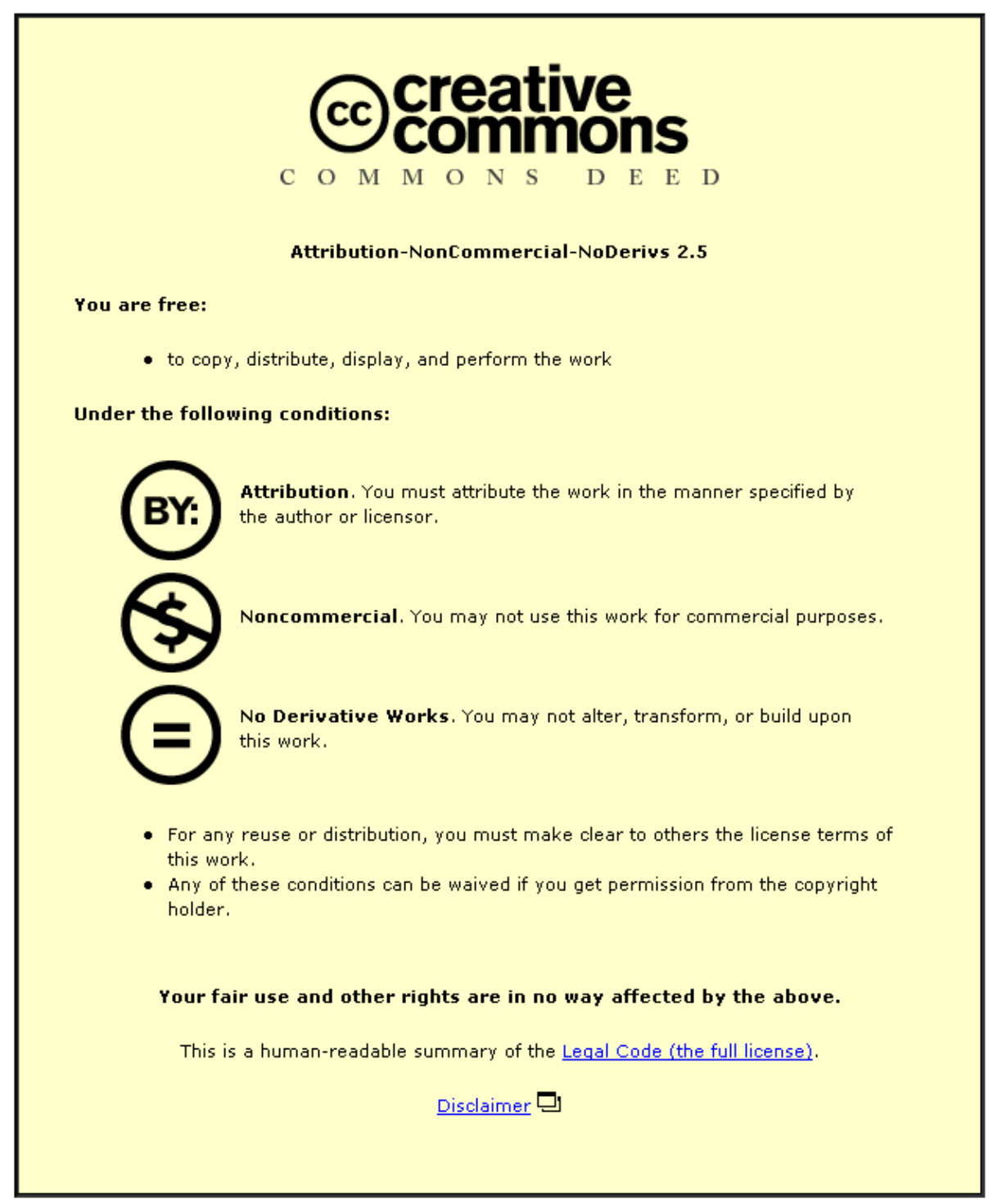

For the full text of this licence, please go to: http://creativecommons.org/licenses/by-nc-nd/2.5/ 


\section{Insulated skin temperature as a measure of core body temperature for individuals wearing CBRN protective clothing}

VL Richmond ${ }^{1}$, DM Wilkinson ${ }^{1}$, SD Blacker ${ }^{1}$, FE Horner ${ }^{1}$, Carter $^{1}$, G Havenith ${ }^{2}$ and MP Rayson ${ }^{1}$

${ }^{1}$ Optimal Performance Ltd, Leigh Court Business Centre, Abbots Leigh, Bristol, UK BS8 3RA vic@optimalperformance.co.uk

${ }^{2}$ Environmental Ergonomics Research Centre, James France Building, Loughborough University, UK LE11 3TU 


\begin{abstract}
This study assessed the validity of insulated skin temperature $\left(\mathrm{T}_{\mathrm{is}}\right)$ to predict rectal temperature $\left(\mathrm{T}_{\mathrm{re}}\right)$ for use as a non-invasive measurement of thermal strain to reduce the risk of heat illness for emergency service personnel. Volunteers from the Police, Fire and Rescue, and Ambulance Services performed role-related tasks in hot $\left(30^{\circ} \mathrm{C}\right)$ and neutral $\left(18^{\circ} \mathrm{C}\right)$ conditions, wearing service specific personal protective equipment. Insulated skin temperature and micro climate temperature $\left(\mathrm{T}_{\mathrm{mc}}\right)$ predicted $\mathrm{T}_{\mathrm{re}}$ with an adjusted $\mathrm{r}^{2}=0.87$ and standard error of the estimate (SEE) of $0.19^{\circ} \mathrm{C}$. A bootstrap validation of the equation resulted in an adjusted $\mathrm{r}^{2}=0.85$ and SEE $=0.20^{\circ} \mathrm{C}$. Taking into account the $0.20^{\circ} \mathrm{C}$ error, the prediction of $\mathrm{T}_{\text {re }}$ resulted in a sensitivity and specificity of $100 \%$ and $91 \%$, respectively. Insulated skin temperature and $\mathrm{T}_{\mathrm{mc}}$ can be used in a model to predict $\mathrm{T}_{\mathrm{re}}$ in emergency service personnel wearing CBRN protective clothing with an SEE of $0.2^{\circ} \mathrm{C}$. However, the model is only valid for $\mathrm{T}_{\text {is }}$ over $36.5^{\circ} \mathrm{C}$, above which thermal stability is reached between the core and the skin.
\end{abstract}

\title{
Keywords
}

Insulated skin temperature; non-invasive temperature measurement; rectal temperature; heat strain; protective clothing

\section{Introduction}

Emergency service (ES) personnel can be placed under considerable physiological and thermal strain during routine operational tasks due to the physical demands of the job, and the protective clothing and breathing apparatus worn. In addition to their regular duties, ES personnel are also required to respond to chemical, biological, radiological and nuclear (CBRN) threats which require an additional level of protection in the form of a fully encapsulated impermeable personal protective equipment (PPE). This potentially creates an environment of uncompensable heat stress which occurs when the heat loss required to maintain heat balance exceeds the maximum evaporative capacity of the clothing system. The clothing restricts evaporative heat loss preventing individuals from dissipating their metabolic heat, which prevents a thermal equilibrium being reached and core body temperature $\left(T_{c}\right)$ continues to increase to exhaustion (Givoni and Goldman, 1972).

It is well documented that by adding CBRN clothing to an already physically demanding job the level of heat strain is exacerbated. McLellan et al. (1993) showed that work tolerance time (WTT) decreased by $41 \%$ when participants wore the highest level of protective clothing worn by the Canadian Forces compared to a lower level of protection. Montain et al. (1994) also showed that WTT decreased by $54 \%$ when full PPE was worn during treadmill walking in a desert environment, compared to partial clothing. Although final $\mathrm{T}_{\mathrm{re}}$ was lower in the full clothing condition in both these studies, final skin temperature $\left(T_{s}\right)$ was higher, resulting in a lower temperature gradient between the skin and the body core, impaired heat loss and a greater sense of thermal strain. This is particularly true for ES personnel; for example in a study which examined the physiological strain associated with firefighters working in CBRN PPE reported a mean increase in $\mathrm{T}_{\mathrm{c}}$ of $1.2^{\circ} \mathrm{C}$ during 30 minutes of drill (Ilmarinen et al., 2004). Similar temperatures 
were reported for police officers during simulated CBRN firearms house entry, with an increase in $\mathrm{T}_{\mathrm{C}}$ of $1.3 \pm 0.1^{\circ} \mathrm{C}$ in 38 minutes and a sweat loss of $1.3 \mathrm{~L} \cdot \mathrm{h}^{-1}$ (Blacker et al., 2012).

Monitoring $\mathrm{T}_{\mathrm{c}}$ during CBRN incidents could reduce the risk of heat illness within ES personnel; however, the measurement of $\mathrm{T}_{\mathrm{c}}$ during occupational deployments is complex, balancing practicality against validity of $T_{c}$ measurement. There are numerous direct measures of $T_{c}$, the most accurate and reliable being the most invasive. These direct measures include rectal temperature $\left(\mathrm{T}_{\mathrm{re}}\right)$ and oesophageal temperature $\left(\mathrm{T}_{\mathrm{es}}\right)$ (Lee et al., 2000, Moran and Mendal, 2002). While being the preferred methods to use in a laboratory environment, these measures are impractical for use in the field due to the associated discomfort, difficulty to safely maintain insertion and hygiene issues (Lee et al., 2000). As other less invasive methods such as tympanic, aural, temporal, oral, axillary and forehead temperatures show less reliable associations with $\mathrm{T}_{\mathrm{re}}$ and $T_{\text {es }}$ (Ganio et al., 2009) it might be more practical to use a non-invasive measure of $T_{c}$, which predicts or estimates deep $T_{c}$.

The possible convergence of $T_{c}$ and skin temperature $\left(T_{s}\right)$ during exercise and/or heat strain indicates $T_{s}$ may be a viable alternative method for the prediction of $T_{c}$. When clothing permeability, in combination with exercise and heat stress, creates a hot, humid microclimate, the conditions are thought to be created for $T_{s}$ to approximate $T_{c}$, even without the presence of thermal insulation (Pandolf and Goldman, 1978). However, even in protective clothing heat transfer is still possible provided there is a positive temperature gradient between the skin and the environment. The diffusion of moisture via evaporation from the skin to the clothing occurs as a result of higher vapour pressure at the skin due to greater skin temperature (Lotens et al., 1995). In addition, any temperature gradient will also allow heat transfer via dry heat exchange. Therefore, even in protective clothing, using an insulation material over the skin thermistor may be necessary to prevent heat loss from the skin at the site of the temperature measurement. The importance of insulating the skin site was highlighted by Buono and Ulrich (1998). Participants walked on a treadmill under three different conditions, with $\mathrm{T}_{\mathrm{s}}$ measured at the chest, calf and forearm. Skin thermistors were either covered with foam and tape, or left exposed to the environment. The covered probes resulted in a significantly higher $\mathrm{T}_{\mathrm{s}}$ in all three conditions, the greatest difference between $\mathrm{T}_{\mathrm{re}}$ and $\mathrm{T}_{\mathrm{s}}\left(1.3^{\circ} \mathrm{C}\right)$ being in a thermoneutral condition $\left(23^{\circ} \mathrm{C}\right)$. The author concluded that covering the probe attenuates heat transfer (particularly conduction, convection and radiation) from the covered area, and drives insulated skim temperature $\left(T_{i s}\right)$ closer to $T_{c}$. While there is little information in the literature on the use of $T_{\text {is }}$ as a predictor of $T_{c}$, the studies available suggest $T_{\text {is }}$ has the potential to estimate $T_{c}$ non-invasively (Taylor et al., 1998, Bernard and Kenney, 1994) and is worthy of investigation for use in the occupational setting. 
The aim of this study was to assess the validity of $T_{\text {is }}$ to predict $T_{\text {re }}$ in police, firefighters and ambulance personnel wearing their respective CBRN PPE.

\section{Methods}

All participants were verbally briefed, issued with a participant information sheet, and gave written informed consent. Ethics approval for the study was granted by the University of Birmingham research ethics committee. Three emergency responder groups participated in the trial, wearing their specific operational CBRN PPE. Twelve participants were recruited from each of the Police and Fire and Rescue Service, and nine were recruited from the Ambulance Service. All participants were medically screened by an occupational physician to ensure they were medically fit to work as determined by the guidelines used by their respective services and were therefore capable of participating in the study.

\section{$2.1 \quad$ Experimental protocol}

Three separate five-day trials were carried out; one for each ES group, resulting in 10 to 14 data sets collected for each ES group. Participants from each ES wore their respective occupational CBRN PPE. Police wore the civil responder 1 (CR1) (Remploy Frontline, Merseyside, UK), a trilayered ensemble with a negative pressure respirator for respiratory protection. Fire and rescue service personnel wore the gas-tight suit (GTS) (Respirex International Ltd, Redhill, Surrey, UK), a one-piece suit worn over the breathing apparatus (BA), in this case being Extended Duration Breathing Apparatus. Ambulance personnel wore the powered respirator protective suit (PRPS) (Respirex International Ltd, Redhill, Surrey, UK) which is also a one-piece suit containing an integral powered respirator system. Underneath the GTS and PRPS participants wore their own choice of clothing as would be standard in a 'live' scenario. In all cases this included either shorts or tracksuit trouser, and a t-shirt. The CR1 incorporates a base layer; therefore Police participants wore only their underwear in addition to the PPE.

Each participant completed four trials in their respective CBRN PPE, on consecutive days. Each trial lasted 60-minutes for the GTS and PRPS groups, and 120-minutes for the CR1 groups. These deployment durations were based on the standard operating procedures for each service in their respective CBRN PPE. Two of the deployments were performed in a 'neutral' thermal environment $\left(\sim 18^{\circ} \mathrm{C}\right)$ and two in a 'hot' environment $\left(\sim 30^{\circ} \mathrm{C}\right)$. These ambient temperatures were chosen to represent typical conditions in the UK. As the trial took place in a large garage style building, it was not possible to manipulate the relative humidity. Each deployment was split into 30 minute circuits (table 1) which included various work-related simulations and rest periods, to simulate a typical "heavy" work schedule replicating a realistic deployment training scenario. Each task lasted 3 minutes and was separated by a 1 minute rest period. The exercise intensity was 
modified (e.g. by manipulating the number of shuttles, height of step) throughout the first trial to ensure the participants were all exercising at the approximately same relative exercise intensity, based on each individual heart rate (HR). The stepping pace was regulated using a metronome. After the first trial, the same circuit schedule was carried out each subsequent day to standardize the exercise challenge.

Table 1. Example of a circuit.

\begin{tabular}{c} 
Task \\
\hline $\begin{array}{c}\text { Brisk walk ( } 5 \text { shuttles } \cdot \mathrm{min}^{-1}-15 \mathrm{~m} \text { for GTS and PRPS and } 20 \mathrm{~m} \text { for CR1 } \\
\text { Stepping }-30 \mathrm{~cm} \text { step at rate of } 15 \mathrm{steps} \cdot \mathrm{min}^{-1}\end{array}$ \\
$30 \mathrm{~m}$ walking shuttle, alternating with and without a Powerbag $(15 \mathrm{~kg}$ ) placed on $0.9 \mathrm{~m}$ \\
table at end of shuttle \\
Brisk walk (5 shuttles per min $-15 \mathrm{~m}$ for GTS and PRPS and $20 \mathrm{~m}$ for CR1 \\
Stepping $-30 \mathrm{~cm}$ step at rate of $15 \mathrm{steps} \cdot \mathrm{min}^{-1}$ \\
$30 \mathrm{~m}$ shuttle, alternating with and without $210 \mathrm{~kg}$ water containers \\
Brisk walk (5 shuttles·min ${ }^{-1}-15 \mathrm{~m}$ for GTS and PRPS and $20 \mathrm{~m}$ for CR1
\end{tabular}

GTS = gas tight suit; CR1 = civil responder 1 and PRPS = powered respirator protective suit

\section{$2.2 \quad$ Measurements}

All participants were monitored for both $\mathrm{HR}$ and $\mathrm{T}_{\mathrm{re}}$ during each deployment. Heart rate was measured using the Polar Team 2 system, (Polar Oy, Kemple, Finland) and $\mathrm{T}_{\mathrm{re}}$ was measured using a flexible probe (Grant Instruments Ltd, Cambridge, UK). Insulated skin temperature (Figure 1) was measured at the lower neck between C7 and T2 (spinous process), consisting of a skin thermistor connected to a Squirrel SQ800 data logger (Grant Instruments Ltd, Cambridge, UK). The probe was covered by a $5 \mathrm{~cm}$ x $5 \mathrm{~cm}$ x $1 \mathrm{~cm}$ block of closed-cell cross linked polyethylene foam (Rubber Astic International, Birmingham, UK), which was secured around the probe head and onto the skin surface by use of a $5 \mathrm{~cm}$ x $5 \mathrm{~cm}$ double-sided adhesive patch (3M Health Care, UK). A further layer of $11 \mathrm{~cm}$ x $11 \mathrm{~cm}$ single-sided adhesive patch (woven spun lace tape 1776, 3M Health Care, UK) was used to cover the polyethylene block and provide additional skin adhesion. Each insulated skin patch had a second probe attached to the outer surface of the patch to monitor the temperature of the microclimate $\left(\mathrm{T}_{\mathrm{mc}}\right)$ directly on top of the skin patch.

Prior to the start of the study all temperature sensors were checked for accuracy over $35^{\circ} \mathrm{C}$ to 41 ${ }^{\circ} \mathrm{C}$ using a precision water bath (GD 100-P12, Grant Instruments, Cambridge, UK) and United Kingdom Accreditation Service Calibrated precision thermometer (T600i, Digitron Ltd, Torquay, UK). All thermistors used in the study were within $0.5{ }^{\circ} \mathrm{C}$ of the precision thermometer after 5 minutes of submersion. 
On day 1 of each test week the participants stature (Seca, Birmingham, UK), body mass (Kern ITT 150K5IP, Kern) and body composition (Harpenden callipers, HaB Intl Ltd, Warwickshire, UK) were determined. Estimated body fat was calculated using the Durnin and Womersley (1974) 4site method. All participants completed a multi-stage fitness test to estimate their aerobic fitness ( $\dot{\mathrm{VO}}_{2} \max$ ) (Ramsbottom et al., 1988). Participants then performed a complete rehearsal of one circuit of the deployment ( 30 minutes) in their regular work clothing of the circuit and fitted their PPE to ensure the sizing was correct. On each day of the deployment participants arrived 90 minutes prior to the start of the trial and were instrumented with $\mathrm{HR}, \mathrm{T}_{\mathrm{re}}$ and $\mathrm{T}_{\text {is }}$ monitors and donned their PPE. The circuit was carried out with six participants at a time, working in teams of three.

There were four reasons for which a test could be terminated: a) attainment of $\mathrm{T}_{\text {re }}$ of $\geq 39.5^{\circ} \mathrm{C}, \mathrm{b}$ ) low air pressure in the breathing apparatus sets in the GTS or low battery to the powered respirator in the PRPS, c) if for any reason the paramedic or support staff felt it was unsafe for the participant to continue, and d) if for any reason the participant felt unable to continue.

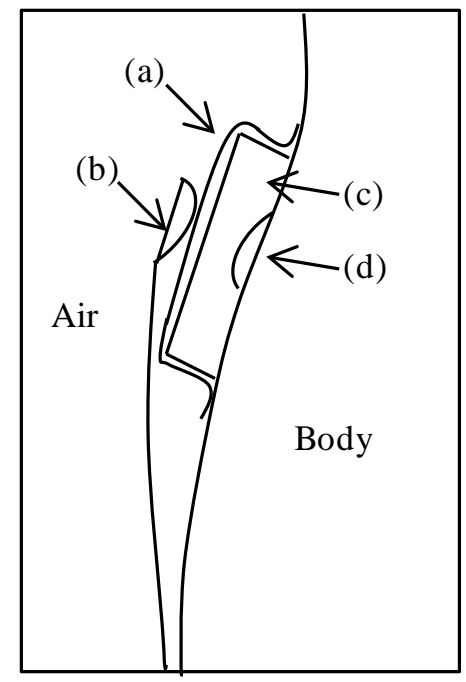

Figure 1 - Insulated skin temperature monitor: (a) $11 \mathrm{~cm}$ x $11 \mathrm{~cm}$ single-sided adhesive patch, (b) thermistor for monitoring micro-climate temperature, (c) $5 \mathrm{~cm} \mathrm{x} 5 \mathrm{~cm}$ x $1 \mathrm{~cm}$ block of closed-cell cross linked polyethylene foam secured to the skin using a double-sided adhesive patch, and (d) temperature thermistor secured at the lower neck under the foam patch.

\subsection{Statistical analysis}

All data are expressed as mean \pm SD. Standard regression analysis techniques were used to determine the association between $\mathrm{T}_{\mathrm{is}}$ and $\mathrm{T}_{\mathrm{re}}$ using SPSS (version 18.0; SPSS Inc., Chicago, Illinois, USA) (Bland, 2000). Where the relationship between $\mathrm{T}_{\mathrm{re}}$ and the primary variable in the 
equation was better described as a curvilinear model, the covariates were centred (c) to reduce colinearity (Bland, 2000). The agreement between measured and predicted $\mathrm{T}_{\mathrm{re}}$ was assessed using Ordinary Least Squared (OLS) regression, reporting the adjusted (adj) $r^{2}$ and the standard estimate of the error (SEE). The level of error between $\mathrm{T}_{\text {is }}$ and $\mathrm{T}_{\mathrm{re}}$ that would be operationally acceptable by the emergency services was determined a-priori as a SEE of $0.2^{\circ} \mathrm{C}$.

The model was validated using a bootstrap technique, in which the model was developed on the data set from all but one individual, and then the equation was validated on the data set that was not used in the development of the model. To assess the validity of the model further, the sensitivity and specificity for identifying individuals over a $\mathrm{T}_{\mathrm{re}}$ of $39{ }^{\circ} \mathrm{C}$ was determined.

\section{Results}

Participant characteristics are shown in table 2. The ambient temperature was $31.0 \pm 1.1^{\circ} \mathrm{C}$ and $18.3 \pm 0.8$ ${ }^{\circ} \mathrm{C}$ and the relative humidity was $27.9 \pm 6.0 \%$ and $56.2 \pm 5.5 \%$ for the hot and neutral conditions over all the three Services' trials, respectively. The mean temperature and relative humidity within the GTS and PRPS throughout the trial were $30.0 \pm 1.8{ }^{\circ} \mathrm{C}$ and $89.3 \pm 6.4 \%$, and $30.6 \pm 3.2{ }^{\circ} \mathrm{C}$ and $88.0 \pm 8.1 \%$, respectively, in the hot conditions; and $25.4 \pm 0.7{ }^{\circ} \mathrm{C}$ and $87.0 \pm 8.0 \%$, and $25.0 \pm 21 .{ }^{\circ} \mathrm{C}$ and $90.8 \pm 10.0 \%$, respectively, in the neutral conditions. Table 3 shows the average HR and \% HRR during the trial for each PPE under each environmental condition.

Table 2. Physical and physiological characteristics of the participants (mean \pm SD).

\begin{tabular}{|c|c|c|c|}
\hline & $\operatorname{CR1}(n=12)$ & GTS $(n=12)$ & PRPS $(n=9)$ \\
\hline Age (years) & $41.1 \pm 6.1$ & $37.2 \pm 6.4$ & $35.2 \pm 6.0$ \\
\hline Body mass (kg) & $83.7 \pm 9.0$ & $82.0 \pm 13.4$ & $79.6 \pm 12.4$ \\
\hline Height (cm) & $177.9 \pm 6.9$ & $176.2 \pm 7.0$ & $176.0 \pm 10.2$ \\
\hline Body fat $(\%)^{*}$ & $26.9 \pm 3.5$ & $24.5 \pm 6.7$ & $21.6 \pm 6.0$ \\
\hline$\dot{\mathrm{V}} \mathrm{O}_{2} \max \left(\mathrm{ml} \cdot \mathrm{kg}^{-1} \cdot \mathrm{min}^{-1}\right)^{* *}$ & $43.9 \pm 5.1$ & $45.9 \pm 8.1$ & $44.4 \pm 5.1$ \\
\hline
\end{tabular}

*estimated from four-site skin-fold measurement (Durnin and Womersley, 1974)

**estimated from the multi-stage fitness test

CR1 = Civil Responder 1 (Police), GTS = Gas Tight Suit (Fire and Rescue service), PRPS = Powered Respirator Protective Suit (Ambulance Service) 
Table 3. Average heart rate (HR) and \% HR reserve (\% HRR) for each PPE in hot $\left(31^{\circ} \mathrm{C}\right)$ and neutral $\left(18^{\circ} \mathrm{C}\right)$ conditions (mean $\pm \mathrm{SD}$ ).

\begin{tabular}{|c|c|c|c|}
\hline & CR1 $(n=12)$ & GTS $(n=12)$ & $\operatorname{PRPS}(n=9)$ \\
\hline \multicolumn{4}{|l|}{ Hot } \\
\hline $\operatorname{HR}\left(b \cdot \min ^{-1}\right)$ & $126 \pm 15$ & $135 \pm 16$ & $137 \pm 17$ \\
\hline HRR (\%) & $57 \pm 11$ & $60 \pm 12$ & $59 \pm 13$ \\
\hline \multicolumn{4}{|l|}{ Neutral } \\
\hline $\mathrm{HR}\left(\mathrm{b} \cdot \mathrm{min}^{-1}\right)$ & $99 \pm 7$ & $120 \pm 10$ & $120 \pm 12$ \\
\hline HRR (\%) & $33 \pm 3$ & $49 \pm 7$ & $46 \pm 9$ \\
\hline
\end{tabular}

\subsection{Comparison between $T_{r e}$ and $T_{\text {is }}$}

Figure 2 shows the raw data of $\mathrm{T}_{\mathrm{re}}$ and $\mathrm{T}_{\text {is }}$ for each group in both hot and neutral conditions (only the first hour of the CR1 trial is included for comparison). The Figure shows that for the GTS and PRPS conditions, $\mathrm{T}_{\text {re }}$ and $\mathrm{T}_{\text {is }}$ converged over the first $20 \mathrm{~min}$ to $30 \mathrm{~min}$ before stabilising. In the CR1 conditions, $\mathrm{T}_{\mathrm{re}}$ and $\mathrm{T}_{\mathrm{is}}$ had stabilized prior to the start of the trial so there was no apparent convergence.
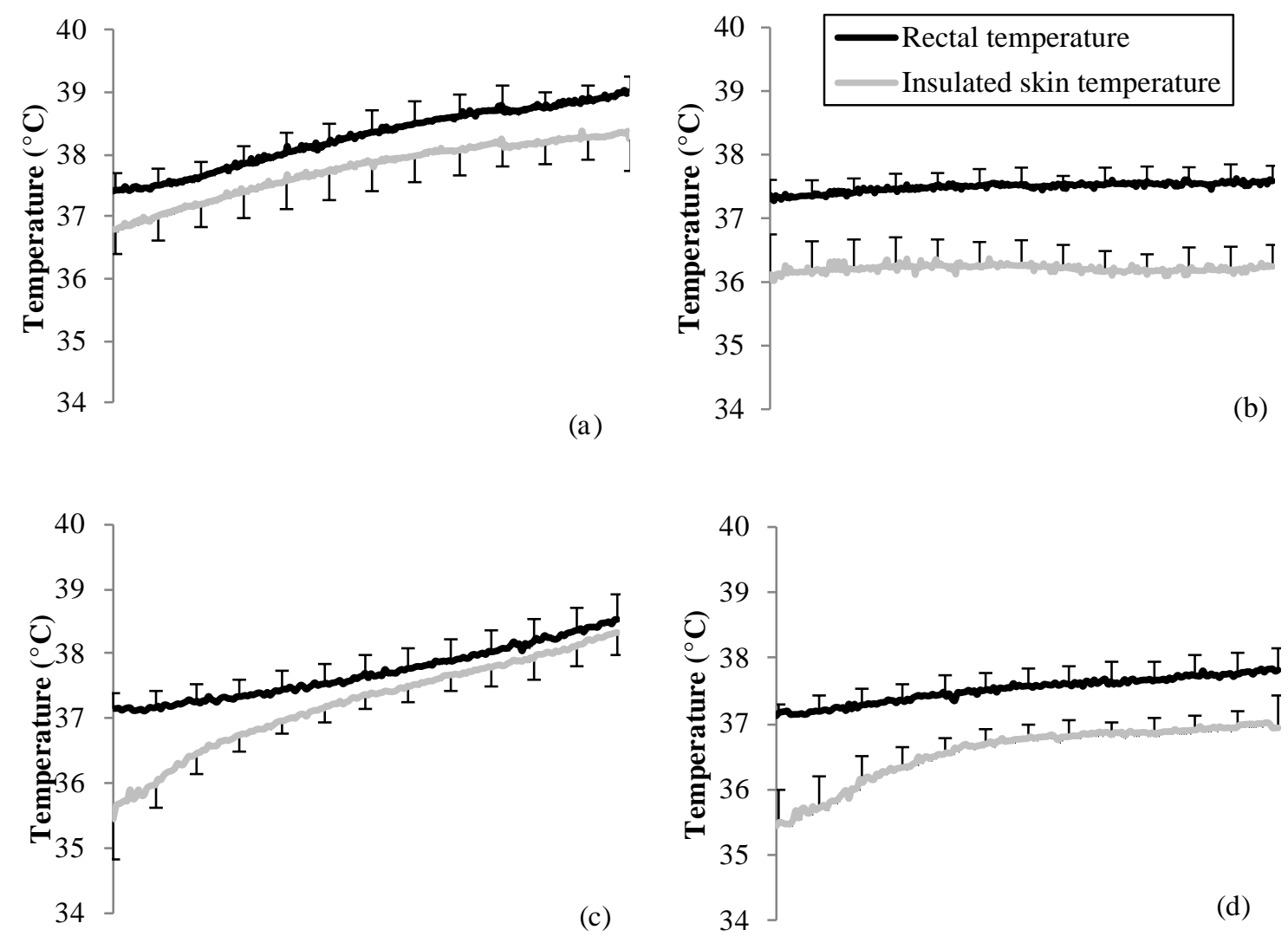

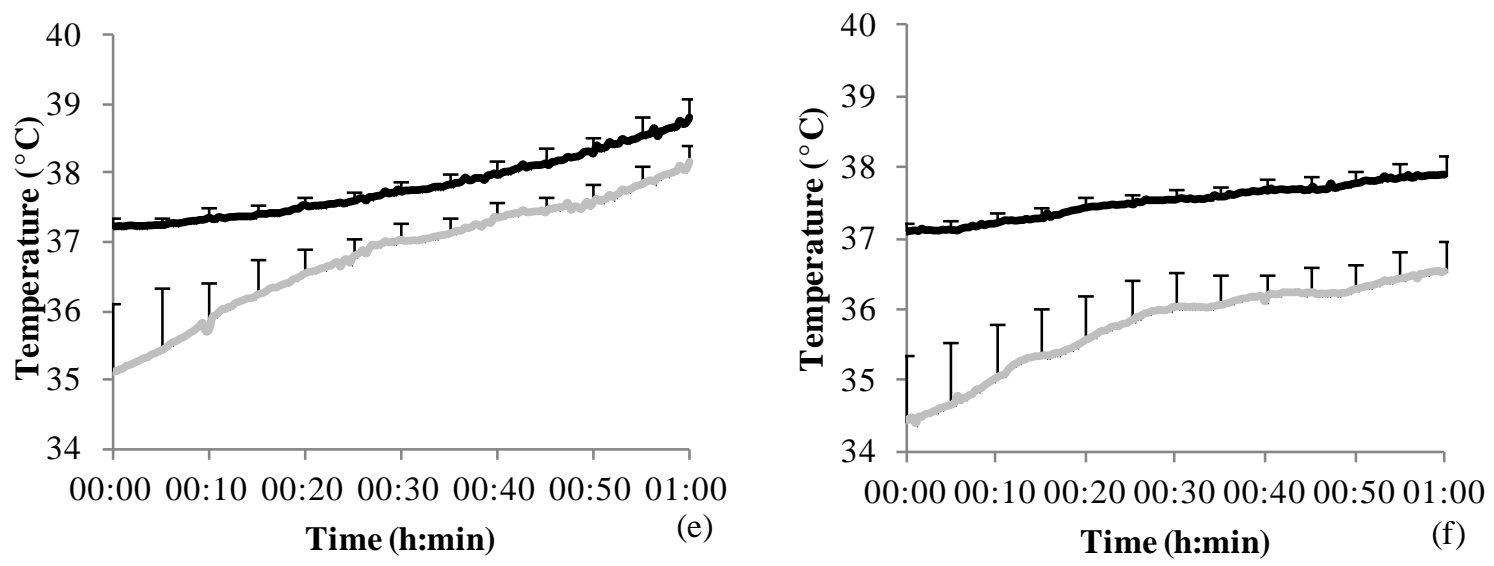

Figure 2 (a-f) - Raw mean data with standard deviation shown every 5 min for clarity for; (a) Civil Responder 1 (CR1) in hot conditions (b) CR1 in cool conditions (c) Gas Tight Suit (GTS) in hot conditions (d) GTS in cool conditions (e) Powered Respirator Protective Suit (PRPS) in hot conditions (f) PRPS in cool conditions. It should be noted that in the CR1 hot and cold conditions the insulated skin temperature (Tis) and rectal temperature (Tre) had converged by the start of the curcuit whereas this did not occur until $25 \mathrm{~min}$ in the GTS and PRPS conditions. This could have been caused by the CR1 ensemble being donned $30 \mathrm{~min}$ before the start of the exercise circuit compared to $5 \mathrm{~min}$ before for the GTS and PRPS ensembles.

Figure 3 shows all the data (at 10 minute intervals) for all deployments combined. The relationship between $T_{\text {re }}$ and $T_{\text {is }}$ was better described as a quadratic equation $\left(r^{2}=0.77\right)$ than a linear equation $\left(r^{2}\right.$ $=0.64$ ). The SEE in predicting $\mathrm{T}_{\mathrm{re}}$ from $\mathrm{T}_{\text {is }}$ alone is $0.64{ }^{\circ} \mathrm{C}$. If $\mathrm{T}_{\text {is }}$ values below $36.5{ }^{\circ} \mathrm{C}$ are removed then there is little difference between the quadratic $\left(r^{2}=0.80\right)$ or the linear $\left(r^{2}=0.78\right)$ equation. Thus, the SEE in predicting $\mathrm{T}_{\mathrm{re}}$ from $\mathrm{T}_{\text {is }}\left(>36.5^{\circ} \mathrm{C}\right)$ using a linear equation was $0.29^{\circ} \mathrm{C}$.

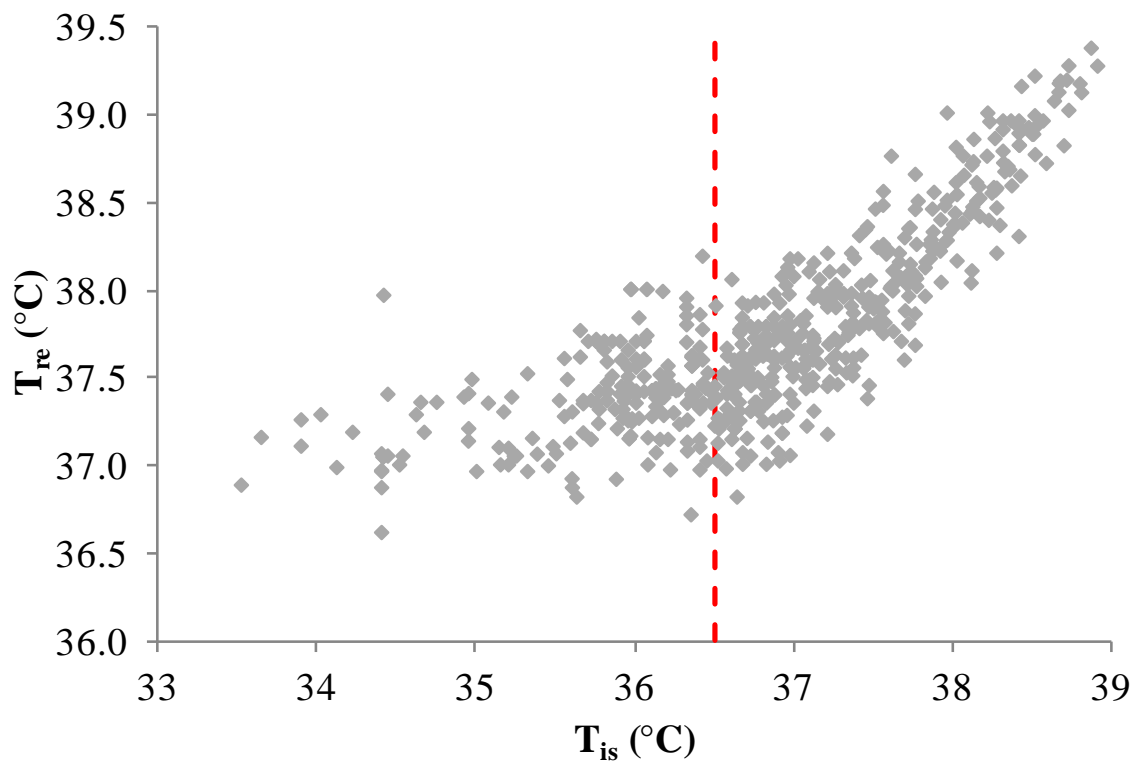


Figure 3 - Relationship between insulated skin temperature $\left(T_{\text {is }}\right)$ and rectal temperature $\left(T_{\text {re }}\right)$

\subsection{Developing a prediction equation}

The data from all conditions (PPE and environmental conditions) at 10 minute intervals were entered into the regression analysis. Due to the curvilinear nature of the relationship between $T_{\text {is }}$ and $T_{r e}, T_{\text {is }}$ was entered into the analysis as a quadratic variable after centring to reduce colinearity, giving an $\mathrm{SEE}=0.25^{\circ} \mathrm{C}$ and an $\operatorname{adjr}^{2}=0.79$.

Using stepwise multiple linear regression the following equation was developed:

$\mathrm{T}_{\mathrm{re}}=37.63+\left(0.604 *\left[\mathrm{cT}_{\mathrm{is}}-36.82\right]\right)+\left(0.130 *\left[\mathrm{cT}_{\mathrm{is}}{ }^{2}-1292\right]\right)-\left(0.070 *\left[\mathrm{cT}_{\mathrm{mc}}-32.16\right]\right)$

$\operatorname{adjr}^{2}=0.79 ;$ SEE $=0.25^{\circ} \mathrm{C}$

Heart rate and 'PPE' did not sufficiently improve the variability in the prediction model to warrant their inclusion $\left(\mathrm{SEE}=0.24^{\circ} \mathrm{C}\right)$. While 'participant' resulted in an improvement in the model $\left(\right.$ adjr $^{2}$ $=0.84$ and $\mathrm{SEE}=0.22{ }^{\circ} \mathrm{C}$ ), it was not included as it would not be practical to have an equation that required individual calibration.

As it was not possible to develop a generic equation to within the pre-defined practical limit of a SEE of less than $0.2^{\circ} \mathrm{C}$, the relationship between $\mathrm{T}_{\text {is }}$ and $\mathrm{T}_{\mathrm{re}}$ was investigated in a sub-set of the data. Figure 3 shows that above a $\mathrm{T}_{\text {is }}$ of $36.5^{\circ} \mathrm{C}$ the relationship between $\mathrm{T}_{\text {is }}$ and $\mathrm{T}_{\mathrm{re}}$ was linear $\left(\mathrm{r}^{2}\right.$ $=0.88$ ). Therefore further analysis was conducted to develop a linear equation using only $\mathrm{T}_{\text {is }}$ data points $\geq 36.5^{\circ} \mathrm{C}$ (Equation 2).

$\mathrm{T}_{\mathrm{re}}=7.07+\left(0.905 * \mathrm{~T}_{\mathrm{is}}\right)-\left(0.088 * \mathrm{~T}_{\mathrm{mc}}\right)$

$\operatorname{adjr}^{2}=0.87 ; \mathrm{SEE}=0.19^{\circ} \mathrm{C}$;

\subsection{Validating the equation}

Twenty seven separate regression equations were developed, each leaving out a different participant from the analysis. Rectal temperature was then predicted for each participant using the equation which was developed without the inclusion of their data set. Figure 4 shows the regression line for predicted (using the 27 equations from the validation of equation 2) against measured $\mathrm{T}_{\mathrm{re}}$. The equations were developed using only $\mathrm{T}_{\mathrm{is}}$ data above $36.5^{\circ} \mathrm{C}$, giving $\mathrm{r}^{2}=0.85$ $(\mathrm{p}<0.05)$ and $\mathrm{SEE}=0.20^{\circ} \mathrm{C}$. Figure 4 also shows the sensitivity and specificity of predicted $\mathrm{T}_{\mathrm{re}}$, with a theoretical upper $\mathrm{T}_{\mathrm{re}}$ limit of $39^{\circ} \mathrm{C}$. Taking into account the error in the model $\left(0.2^{\circ} \mathrm{C}\right)$, to protect $97.5 \%$ of individuals from exceeding a $\mathrm{T}_{\mathrm{re}}$ of $39{ }^{\circ} \mathrm{C}$, participants would need to stop exercising at a predicted $\mathrm{T}_{\mathrm{re}}$ of $38.6^{\circ} \mathrm{C}$, which protected all participants from exceeding the limit (sensitivity $100 \%$ ). In protecting most individuals from possible heat illness, many individuals 
would be stopped at an actual $\mathrm{T}_{\mathrm{c}}$ of well below (between $38.2{ }^{\circ} \mathrm{C}$ and $39{ }^{\circ} \mathrm{C}$ ) the designated $\mathrm{T}_{\mathrm{re}}$ limit (bottom right quadrant of Figure 4) (specificity $89 \%$ ). If the known error was not taken into account, and all individuals were stopped at a predicted $\mathrm{T}_{\mathrm{re}}$ of $39^{\circ} \mathrm{C}$, the sensitivity and specificity would be $65 \%$ and $100 \%$, respectively.

Taking the mean value of the coefficients from the 27 equations, the following equation was created:

$\mathrm{T}_{\mathrm{re}}=7.07+\left(0.905 * \mathrm{~T}_{\mathrm{is}}\right)-\left(0.088 * \mathrm{~T}_{\mathrm{mc}}\right)$

$\operatorname{adjr}^{2}=0.85 ;$ SEE $=0.20^{\circ} \mathrm{C}$

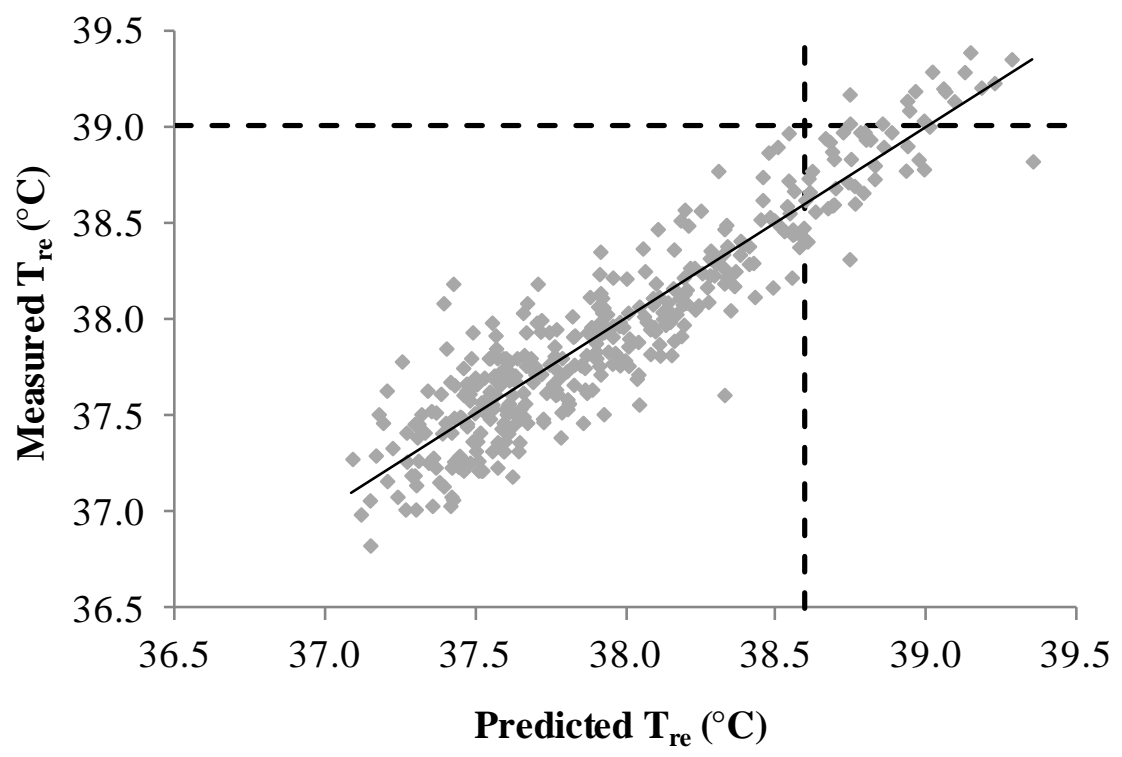

Figure 4 - Predicted vs. measured rectal temperature $\left(\mathrm{T}_{\mathrm{re}}\right)\left({ }^{\circ} \mathrm{C}\right)$. The dashed lines show participants would need to be stopped at a predicted $\mathrm{T}_{\mathrm{re}}$ of $38.6^{\circ} \mathrm{C}$ to prevent $97.5 \%$ of the population exceeding actual $39^{\circ} \mathrm{C}$. 
The aim of this study was to investigate the validity of using $T_{\text {is }}$ to predict $T_{\text {re }}$ in $E S$ personnel wearing CBRN PPE. A prediction model using $T_{\text {is }}$ and $T_{\mathrm{mc}}$ was developed for the prediction of $T_{\mathrm{re}}$ within a predetermined practical target SEE of $\leq 0.2^{\circ} \mathrm{C}$. Validation of the model using bootstrapping techniques showed that the equation could be applied to a separate cohort, within the target SEE of $0.2^{\circ} \mathrm{C}$.

Although there are no studies which use $T_{\text {is }}$ to develop a heat strain index, the concept of using $T_{s}$ to derive information about the thermal status of the body core is not novel. In 1971, Fox and Solman proposed a new method of body temperature measurement, based on heat insulation and equalisation of the skin and deep temperatures (Fox and Solman, 1971). If heat dissipation from the core to the environment is minimized either by insulation of the skin or due to conditions of uncompensable heat stress, $T_{s}$ will converge with $T_{c}$ and the temperature of the skin will eventually reflect changes in the core temperature (Pandolf and Goldman, 1978). The data from the current study show that $T_{s}$ converges towards $T_{r e}$ when heat loss from the skin is minimized, and the difference between the two temperature measurements eventually stabilizes. The onset of exercise causes an increase in metabolic heat production which is accompanied by a rise in internal temperature. Above a certain threshold, thermoregulatory responses are evoked (Johnson and Park, 1982), including cutaneous vasodilation which promotes an increase in skin blood flow for dry heat loss from the skin to the environment. The extent to which $\mathrm{T}_{\mathrm{s}}$ and $\mathrm{T}_{\mathrm{re}}$ converge (ranging from 0.1 ${ }^{\circ} \mathrm{C}$ to $1.5^{\circ} \mathrm{C}$ in the current study) depends upon the temperature of the microclimate (Kenefick et al., 2010), but once thermal equilibrium between the two measures is reached, $T_{r e}$ and $T_{s}$ should rise in parallel. In GTS and PRPS, $\mathrm{T}_{\text {is }}$ and $\mathrm{T}_{\mathrm{re}}$ converged for the first 20 to $30 \mathrm{~min}$ of exercise, after which they increased in parallel for the remainder of the trial. In CR1 there was no convergence, with $\mathrm{T}_{\text {is }}$ and $\mathrm{T}_{\mathrm{re}}$ tracking each other in parallel for the entirety of the trial. The difference in time taken to reach thermal equilibrium between the ensembles was due to the fact that the GTS and PRPS were donned immediately prior to the start of exercise in order to conserve air from the BA (GTS) or conserve the battery life of the powered respirator (PRPS). The CR1 ensemble was donned 30 minutes before the participants started the exercise circuit (excluding the respirator, which is donned immediately prior to deployment). This is due to the more complex procedure of dressing in three layers of the CR1 in comparison to the one layer GTS and PRPS ensembles, which were donned 5 minutes before the start of the exercise circuit. This allowed a thermal equilibrium between $\mathrm{T}_{\mathrm{re}}$ and $\mathrm{T}_{\text {is }}$ to be reached prior to the start of exercise in the CR1 conditions (Figure 2). Smolander et al. (1984) showed that $\mathrm{T}_{\mathrm{s}}$ converged with $\mathrm{T}_{\mathrm{re}}$ for the first 20 minutes of exercise in protective clothing, before reaching thermal equilibrium, with participants exercising at $41 \% \dot{\mathrm{VO}}_{2}$ max in a $24{ }^{\circ} \mathrm{C}$ environment. Nunneley et al. (1992) also showed that $\mathrm{T}_{\mathrm{s}}$ and $\mathrm{T}_{\mathrm{re}}$ 
reached thermal equilibrium after 20 min of exercise for participants wearing protective clothing, even when the high ambient temperature $\left(38^{\circ} \mathrm{C}\right.$ ) caused $\mathrm{T}_{\mathrm{s}}$ to rise to a higher temperature than the core. These studies suggest that 20 minutes should allow for thermal equilibrium (equal difference between skin and core over time) to be reached in protective clothing, although this study shows this could be closer to 30 min depending on exercise intensity and environmental conditions.

Despite the convergence and apparent stability between $T_{r e}$ and $T_{i s}, T_{\text {is }}$ as a stand-alone measurement resulted in an SEE of $0.29^{\circ} \mathrm{C}$ and therefore could not predict $\mathrm{T}_{\mathrm{re}}$ with the desired precision of $0.2^{\circ} \mathrm{C}$. Other studies investigating the prediction of $\mathrm{T}_{\mathrm{c}}$ from $\mathrm{T}_{\text {is }}$ have also questioned the error associated with the relationship. Although these studies will provide useful insight into a measure for which there is little research available, the protocols have little in common with the current study; thus, this caveat must be considered when drawing comparisons between studies. Bogh and colleagues (1994) compared $\mathrm{T}_{\text {is }}$ measured at the chest and axillia against $\mathrm{T}_{\mathrm{re}}$ during a study to examine the effect of circadian rhythm on body temperature. Despite some agreement between $T_{\text {re }}$ and $T_{\text {is }}$ at the chest, the study concluded the $T_{\text {is }}$ measurement could not act as a substitute for $\mathrm{T}_{\mathrm{re}}$, particularly during physical activity. The authors suggested that the cotton wool insulation material used was not adequate and questioned whether this could be improved due to inconvenience to the participant of a thicker insulation material and possible allergic reaction to additional adhesive. In another similar study investigating the circadian rhythm of adult women, the correlation between $T_{\text {re }}$ and $T_{\text {is }}$ was found to be variable and the authors concluded it should not be considered a substitute for $T_{\text {re }}$ (Thomas et al., 2004). One study has found that $T_{\text {is }}$ alone is a surrogate measure of $\mathrm{T}_{\mathrm{re}}$ (Bernard and Kenney, 1994). In that study a device was designed that consisted of a $2.5 \mathrm{~cm}$ thermally conducting copper disk, covered with insulator that was $4.2 \mathrm{~cm}$ in diameter and $0.8 \mathrm{~cm}$ thick. There was a high correlation between $\mathrm{T}_{\mathrm{re}}$ and disk temperature $(\mathrm{r}=$ 0.93) with an SEE of $0.2^{\circ} \mathrm{C}$.

Although the current study has shown it is not possible to use $T_{\text {is }}$ alone as a predictor of $T_{\text {re }}$, a regression equation which included $\mathrm{T}_{\mathrm{mc}}$ was developed that did provide a viable and practical noninvasive measure of $\mathrm{T}_{\mathrm{re}}$. Only Taylor (1998) has previously used a regression equation that was developed for the prediction of $\mathrm{T}_{\text {es }}$ using $\mathrm{T}_{\text {is }}$ (measured at the spinous process). Three equations were developed, one for each of three environmental conditions $\left(25^{\circ} \mathrm{C}, 33^{\circ} \mathrm{C}\right.$ and $\left.40^{\circ} \mathrm{C}\right)$, with strong correlations reported ranging from 0.8 to 0.9 across all conditions. In the current study, $\mathrm{T}_{\mathrm{mc}}$ was found to improve the error in the prediction of $\mathrm{T}_{\mathrm{re}}$. Figure 2 showed that the difference between $T_{\text {re }}$ and $T_{\text {is }}$ varies depending on the ambient temperature; lower ambient temperature is associated with a larger difference between $\mathrm{T}_{\mathrm{re}}$ and $\mathrm{T}_{\mathrm{is}}$. This was also shown by McLellan et al. (1993) where the difference between $\mathrm{T}_{\mathrm{re}}$ and mean $\mathrm{T}_{\mathrm{s}}$ was $1.3^{\circ} \mathrm{C}$ and $2.2^{\circ} \mathrm{C}$ when ambient temperatures were $30^{\circ} \mathrm{C}$ and $18^{\circ} \mathrm{C}$, respectively, for firefighters carrying out heavy work in CBRN 
PPE. Microclimate temperature clearly has a direct impact on the degree to which $T_{\text {is }}$ and $T_{\text {re }}$ converge (McLellan et al., 1993, Kenefick et al., 2010), and the inclusion of $\mathrm{T}_{\mathrm{mc}}$ in the equation (equation 3) improves the prediction of $\mathrm{T}_{\mathrm{re}}$. However, $\mathrm{T}_{\mathrm{mc}}$ is subtracted, or inversely in the equation, which is counterintuitive based on the assumption that as $\mathrm{T}_{\mathrm{mc}}$ increases, capacity for heat loss decreases, which is likely to result in an increase in $\mathrm{T}_{\mathrm{re}}$. To the contrary, this equation (equation 3 ) suggests that a higher $\mathrm{T}_{\mathrm{mc}}$ has the effect of reducing $\mathrm{T}_{\mathrm{re}}$, but the reasons and unclear from the results of this study.

Unfortunately, the exercise protocol used in the current study limits the extent to which one can generalize the findings to other exercise scenarios. In the current study, despite short rest periods between exercise bouts, the overall trend in all physiological responses was to increase. While representative of a short deployment in CBRN according to standard operating procedures enforced by the ESs, this is not representative of all working situation, in which an individual may be working in a high heat stress condition discontinuously for several hours, including many periods of work and rest (Blacker et al., 2012). For a non-invasive monitor to be valid under these circumstances, it must be able to predict $\mathrm{T}_{\mathrm{re}}$ during both increases and decreases in body temperature. Further work is required to determine the validity of $T_{\text {is }}$ to predict $T_{\text {re }}$ under other conditions and patterns of work and rest.

\subsection{Application of the model in a working environment}

The impact of the error in predicting $\mathrm{T}_{\mathrm{re}}$ on the workforce must be considered, and will depend very much on the safety criteria set and the risk the employer is willing to take. Collapse from heat stroke is usually associated with a $\mathrm{T}_{\mathrm{c}}$ of $>40^{\circ} \mathrm{C}$ (Armstrong, 2003). While in reality many individuals will cope at temperatures between $39^{\circ} \mathrm{C}$ to $40^{\circ} \mathrm{C}$, this is not an acceptable upper limit in a working environment, especially taking into consideration that the critical $\mathrm{T}_{\mathrm{c}}$ for individuals working in conditions of uncompensable heat stress is often reported as $38.5^{\circ} \mathrm{C}$ (Montain et al., 1994, Selkirk and McLellan, 2001). Using this criterion (38.5 ${ }^{\circ} \mathrm{C}$ ), and the SEE of $0.20^{\circ} \mathrm{C}$, individuals would have to be removed from work at a predicted $\mathrm{T}_{\mathrm{re}}$ of $38.1^{\circ} \mathrm{C}$. While this would mean only $2.5 \%$ of the population risk being above $38.5^{\circ} \mathrm{C}$, another $2.5 \%$ would also be stopping at below $37.7^{\circ} \mathrm{C}$, having an adverse effect on work productivity. By increasing the $\mathrm{T}_{\mathrm{c}}$ limit, work productivity could be improved, but this must be balanced against the additional risk of heat illness to the work force. Another option is to change the probability of risk to 1 SD rather than 2 SD, and in doing so protect $84 \%$ of the population. This would result in workers being stopped at a predicted $\mathrm{T}_{\text {re }}$ of $38.3^{\circ} \mathrm{C}$, but would mean that $16 \%$ of the population would be working above 38.5 ${ }^{\circ} \mathrm{C}$. There is no definitive solution to this safety dilemma, and opinion varies. Gant et al. (2006) cited $0.3^{\circ} \mathrm{C}$ (95\% limits of agreement [approximately $\pm 2 \mathrm{SD}$ ]) as an acceptable error between $\mathrm{T}_{\mathrm{re}}$ and gastro-intestinal temperature, with Gunga et al. (2009) accepting an error (95 \% limits of 
agreement [approximately $\pm 2 \mathrm{SD}$ ]) of $0.5^{\circ} \mathrm{C}$ between $\mathrm{T}_{\text {re }}$ and a heat-flux sensor. Conversely, Muir et al. (2001) stated that an SD of $0.1^{\circ} \mathrm{C}$ was required to ensure the accuracy of prediction between $\mathrm{T}_{\mathrm{re}}$ and aural temperature. Ultimately the decision and consequent trade-offs lie with the employer, but the application of the model must be considered by the researcher to determine the viability of the surrogate measure.

\subsection{Conclusion}

The results from this study suggest that $T_{\text {is }}$ and $T_{m c}$ can be used in a model to predict $T_{\text {re }}$ in ES personnel wearing different CBRN PPE ensembles within an SEE of $0.20^{\circ} \mathrm{C}$. The model is only applicable when $\mathrm{T}_{\text {is }}$ is over $36.5^{\circ} \mathrm{C}$, above which thermal stability is reached between the body core and the skin. Future work should involve determining the viability of using this non-invasive method in other physically demanding occupations performing different work-rest scenarios in different climatic conditions.

ARMSTRONG, L. E. (2003) Exertional Heat Illness, USA, Human Kinetics, Inc.

BERNARD, T. E. \& KENNEY, W. L. (1994) Rationale for a personal monitor for heat strain. Am Ind Hyg Assoc J, 55, 505-14.

BLACKER, S. D., CARTER, J. M., WILKINSON, D. M., RICHMOND, V. L., RAYSON, M. P. \& PEATTIE, M. (2012) Physiological responses of Police Officers during job simulations wearing chemical, biological, radiological and nuclear personal protective equipment. Ergonomics, 56, 137-47.

BLAND, J. M. (2000) An Introduction to Medical statistics, Oxford, Oxford University Press.

BOGH, M., MINORS, D. S. \& WATERHOUSE, J. M. (1994) Can insulated skin temperature act as a substitute for rectal temperature when studying circadian rhythms? Chronobiol Int, 11, 332-9.

BUONO, M. J. \& ULRICH, R. L. (1998) Comparison of mean skin temperature using 'covered' versus 'uncovered' contact thermistors. Physiol Meas, 19, 297-300.

DURNIN, J. V. \& WOMERSLEY, J. (1974) Body fat assessed from total body density and its estimation from skinfold thickness: measurements on 481 men and women aged from 16 to 72 years. British Journal of Nutrition, 32, 77-97.

FOX, R. H. \& SOLMAN, A. J. (1971) A new technique for monitoring the deep body temperature in man from the intact skin surface. $J$ Physiol, 212, 8P-10P.

GANIO, M. S., BROWN, C. M., CASA, D. J., BECKER, S. M., YEARGIN, S. W., MCDERMOTT, B. P., BOOTS, L. M., BOYD, P. W., ARMSTRONG, L. E. \& MARESH, C. M. (2009) Validity and reliability of devices that assess body temperature during indoor exercise in the heat. J Athl Train, 44, 124-35.

GANT, N., ATKINSON, G. \& WILLIAMS, C. (2006) The validity and reliability of intestinal temperature during intermittent running. Med Sci Sports Exerc, 38, 1926-31.

GIVONI, B. \& GOLDMAN, R. F. (1972) Predicting rectal temperature response to work, environment, and clothing. J Appl Physiol, 32, 812-22.

GUNGA, H. C., WERNER, A., STAHN, A., STEINACH, M., SCHLABS, T., KORALEWSKI, E., KUNZ, D., BELAVY, D. L., FELSENBERG, D., SATTLER, F. \& KOCH, J. (2009) 
The Double Sensor-A non-invasive device to continuously monitor core temperature in humans on earth and in space. Respir Physiol Neurobiol, 169 Suppl 1, S63-8.

ILMARINEN, R., LINDHOLM, H., KOIVISTOINEN, K. \& HELISTEN, P. (2004) Physiological evaluation of chemical protective suit systems (CPSS) in hot conditions. Int J Occup Saf Ergon, 10, 215-26.

JOHNSON, J. M. \& PARK, M. K. (1982) Effect of heat stress on cutaneous vascular responses to the initiation of exercise. $J$ Appl Physiol, 53, 744-9.

KENEFICK, R. W., CHEUVRONT, S. N., PALOMBO, L. J., ELY, B. R. \& SAWKA, M. N. (2010) Skin temperature modifies the impact of hypohydration on aerobic performance. Journal of Applied Physiology, 109, 79-86.

LEE, S. M. C., WILLIAMS, W. J. \& FORTNEY SCHNEIDER, S. M. (2000) Core temperature measurement during supine exercise: esophageal, rectal and intestinal temperatures Aviat Space Environ Med, 71, 939-945.

LOTENS, W. A., VAN DE LINDE, F. J. \& HAVENITH, G. (1995) Effects of condensation in clothing on heat transfer. Ergonomics, 38, 1114-31.

MCLELLAN, T. M., JACOBS, I. \& BAIN, J. B. (1993) Influence of temperature and metabolic rate on work performance with Canadian Forces NBC clothing. Aviat Space Environ Med, 64, 587-94.

MONTAIN, S. J., SAWKA, M. N., CADARETTE, B. S., QUIGLEY, M. D. \& MCKAY, J. M. (1994) Physiological tolerance to uncompensable heat stress: effects of exercise intensity, protective clothing, and climate. J Appl Physiol, 77, 216-22.

MORAN, D. S. \& MENDAL, L. (2002) Core temperature measurement: methods and current insights. Sports Med, 32, 879-85.

MUIR, I. H., BISHOP, P. A., LOMAX, R. G. \& GREEN, J. M. (2001) Prediction of rectal temperature from ear canal temperature. Ergonomics, 44, 962-72.

NUNNELEY, S. A., ANTUNANO, M. J. \& BOMALASKI, S. H. (1992) Thermal convergence fails to predict heat tolerance limits. Aviat Space Environ Med, 63, 886-90.

PANDOLF, K. B. \& GOLDMAN, R. F. (1978) Convergence of skin and rectal temperatures as a criterion for heat tolerance. Aviat Space Environ Med, 49, 1095-1101.

RAMSBOTTOM, R., BREWER, J. \& WILLIAMS, C. (1988) A progressive shuttle run test to estimate maximal oxygen uptake. Br J Sports Med, 22, 141-4.

SELKIRK, G. A. \& MCLELLAN, T. M. (2001) Influence of aerobic fitness and body fatness on tolerance to uncompensable heat stress. J Appl Physiol, 91, 2055-63.

SMOLANDER, J., LOUHEVAARA, V., TUOMI, T., KORHONEN, O. \& JAAKKOLA, J. (1984) Cardiorespiratory and thermal effects of wearing gas protective clothing. Int Arch Occup Environ Health, 54, 261-70.

TAYLOR, N. A., B.R. WILSMORE, AMOS, D., T. TAKKEN, T. KOMEN, COTTER, J. D. \& JENKINS, A. (1998) Indirect measurement of core temperature during work clothing and environmental influences. Environ Erg, 325-328.

THOMAS, K. A., BURR, R., WANG, S. Y., LENTZ, M. J. \& SHAVER, J. (2004) Axillary and thoracic skin temperatures poorly comparable to core body temperature circadian rhythm: results from 2 adult populations. Biol Res Nurs, 5, 187-94. 